\title{
Correction to: Therapeutic effects of royal jelly against sodium benzoate induced toxicity: cytotoxic, genotoxic and biochemical assessment
}

\author{
Ali Acar $^{1}$ (D) \\ Published online: 4 May 2021 \\ (C) Springer-Verlag GmbH Germany, part of Springer Nature 2021
}

\section{Correction to: Environmental Science and Pollution Research} https://doi.org/10.1007/s11356-021-13172-6

Equation 5 in the original article was published with an error. In the original article, the relevant data were calculated with the correct equation. No data change has been made.

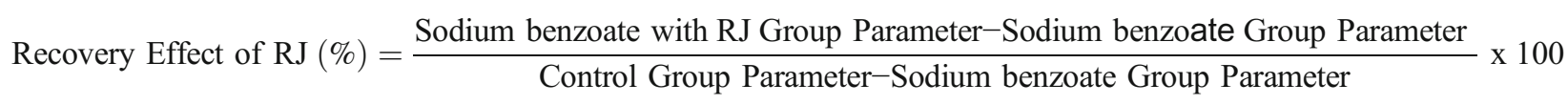

Publisher's note Springer Nature remains neutral with regard to jurisdictional claims in published maps and institutional affiliations.

The online version of the original article can be found at https://doi.org/ 10.1007/s11356-021-13172-6

\footnotetext{
Ali Acar

aliacar@outlook.com

1 Department of Medical Services and Techniques, Vocational School of Health Services, Giresun University, Giresun, Turkey
} 